\title{
Coupled gas chromatographic-electroantennographic responses of Xanthogaleruca luteola (Müller) (Coleoptera: Chrysomelidae) to volatile organic compounds from Eucalyptus globulus extract
}

\author{
Luis Reyes-García ${ }^{1 *}$, Fabian Lizama ${ }^{1}$, Valeska Roldan ${ }^{1}$, Carmen Troncoso ${ }^{1}$, and Marcos Flores ${ }^{1}$ \\ ${ }^{1}$ Universidad Santo Tomás, Facultad de Ciencias, Departamento de Ciencias Básicas, Limonares 190, Viña del Mar, Chile. \\ *Corresponding author (luisreyesga@santotomas.cl).
}

Received: 31 August 2020; Accepted: 15 November 2020; doi:10.4067/S0718-58392021000100119

\begin{abstract}
Xanthogaleruca luteola (Müller) is a monophagous pest species indigenous to Europe, known as elm leaf beetle. During the larval and adult stages, this insect damages elm leaves as it chews small holes in the leaves, causing, even, complete defoliation, leaving only the nervation. Although this species only uses Ulmus spp. as host plants to complete its development, some preliminary results have shown that is attracted to non-host plants such as Eucalyptus globulus Labill. In order to understand the role of volatile organic compounds emitted by E. globulus when the insect is attracted to this non-host plant, dichloromethane extracts of E. globulus were analyzed through gas chromatography-mass spectrometry, and main compounds were identified. Likewise, to evaluate the response of the antennae in X. luteola males and females to the compounds contained in the extract, a gas chromatographic-electroantennographic detection (GC-EAD) was conducted. Only females were observed to respond to $\alpha$-pinene, eucalyptol, 4 -terpineol, $\alpha$-terpineol, $\alpha$-terpineol acetate, $\alpha$-gurjunene, alloaromadendrene, alloaromadendrene, viridiflorene, and globulol compounds. This study is the first step to identify substances mediating the host plant selection of $X$. luteola.
\end{abstract}

Key words: Electroantennography, elm leaf beetle, insect behavior, olfactometry.

\section{INTRODUCTION}

The species Xanthogaleruca luteola (Müller) (Coleoptera: Chrysomelidae), known locally as elm leaf beetle, is native to the Northern Hemisphere, phytophagous and one of the most severe defoliators of trees of the Ulmus genus (Ulmaceae) (Luna et al., 2015) which it uses as a host. In its larval stage, this species consumes the leaf parenchyma, leaving only the nervation. The damage generated in its larval and adult stage finally causes leaf abscission (Huerta et al., 2011), influencing the loss of plants of great value for green areas. In Chile, the presence of this species was first detected in 1994 in Valparaiso and it is currently distributed throughout the central zone up to La Araucanía Region (SAG, 2010). The life cycle of this beetle is approximately 4 mo with at least three generations per year (Huerta et al., 2011). Several control strategies have been used to control this pest, including the application of organochlorine and phosphorous insecticides, and the use of natural enemies for biocontrol (Büchel et al., 2014). Despite the strategies used to control this pest, there are currently no official control programs for this insect. Although this species only uses Ulmus spp. as host plants to complete its development, some preliminary results have shown that it is attracted to non-host plants such as Eucalyptus globulus (Nahrung et al., 2016). 
Several secondary metabolites produced and emitted by E. globulus specimens exert effects on insect physiology and behavior, playing an important role in the plant-insect interaction (Bouwer et al., 2014). In order to understand the role of volatile organic compounds emitted by E. globulus when the insect is attracted to this non host-plant, dichloromethane extracts of E. globulus were analyzed through gas chromatography-mass spectrometry to identify main compounds and extract's composition. Furthermore, in order to evaluate interactions mediated by volatile organic compounds, the antenna response of male and female $X$. luteola to compounds contained in the dichloromethane extracts by means of gas chromatographic-electroantennographic detection (GC-EAD) was evaluated.

\section{MATERIALS AND METHODS}

Adult Xanthogaleruca luteola (Müller) specimens were collected from the eucalyptus host in several locations near Viña del Mar (3302' S, 71 ${ }^{\circ} 31^{\prime}$ W), Valparaiso Region, central Chile, between June and December 2018. The insects were kept in a climatic chamber $\left(25 \pm 1{ }^{\circ} \mathrm{C} ; 16: 8 \mathrm{~h}\right.$ photoperiod; $\left.50 \pm 5 \% \mathrm{RH}\right)$ and fed with leaves of the host Eucalyptus globulus Labill.

The insects were observed in a binocular stereoscopic loupe and sexed according to characteristics previously described by Huerta et al. (2011), they were placed individually in plastic receptacles $(n=395)$, and kept in a climatic chamber in conditions similar to those described above.

\section{Eucalyptus essential oil extraction and analysis}

Eucalyptus globulus fresh leaves were randomly collected from trees located near the Universidad Santo Tomas, Viña del Mar. The extraction of the essential oil was carried out from $50 \mathrm{~g}$ fresh leaves ground in a mortar to approximate $1 \mathrm{~mm}$ in diameter, applying later the technique of steam distillation. For the liquid-liquid extraction dichloromethane was used, the organic phase was dried through the passage of a funnel with filter paper containing $\mathrm{Na}_{2} \mathrm{SO}_{4}$, and then, it was concentrated in a rotavapor (IKA RV-10, IKA-Werke GmbH \& Co. KG, Staufen, Germany) at reduced pressure and the oil was stored at $-20{ }^{\circ} \mathrm{C}$ until its subsequent analysis.

For the gas chromatography analysis coupled to a mass spectrometer(GC-MS), a gas chromatograph-mass spectrometer (GC-MS-QP2010 Ultra, Shimadzu, Kyoto, Japan) equipped with a fused silica GC column (Rtx-5, Restek Corporation, Bellefonte, Pennsylvania, USA) was used, the temperature program used was $50^{\circ} \mathrm{C}$ for 5 min up to $270{ }^{\circ} \mathrm{C}$ with a heating ramp of $8{ }^{\circ} \mathrm{C} \mathrm{min}{ }^{-1}$. Helium was used as a carrier gas. The mass spectrum was acquired at $70 \mathrm{eV}$ and the $\mathrm{GC}$ was operated in splitless mode with the injector at $250{ }^{\circ} \mathrm{C}$.

\section{Electrophysiology}

For the electrophysiological studies, a GC-2014AFSC GC (Shimadzu) was used, coupled to a flame ionization detector (FID) and an electroantennographic detector (EAD) (Syntech, Kirchzarten, Germany). The gas chromatograph was equipped with an Rtx-Wax fused silica capillary column $(30 \mathrm{~m} \times 0.32 \mathrm{~mm}$ id, $0.25 \mu \mathrm{m}$ film; Restek Corporation, Bellefonte, Pennsylvania, USA) and helium was used as carrier gas. The effluent from the column was divided into two equal parts; one part towards the FID and the other towards a transfer line heated to $204{ }^{\circ} \mathrm{C}$ with an output to a humidifier terminal $\left(400 \mathrm{~mL} \mathrm{~min}^{-1}\right)$ where the insect antenna was directly arranged. The antennae were prepared by decapitating the insect and connecting the base of the head and the tips of both antennae to the two electrodes of the probe (Figure 1) covered with conducting gel (SYNTECH probe, Ockenfels SYNTECH GmbH, Buchenbach, Germany) (Bergmann et al., 2016). The correct assembly of the antenna was verified by mechanical stimulation and with dichloromethane extract. The signal was acquired through the IDAC-2 acquisition interface (SYNTECH), and it was recorded and processed with the GC-EAD 2010 software v1.2.2 (Ockenfels SYNTECH GmbH). Four antennae, from both females and males, were analyzed.

\section{RESULTS AND DISCUSSION}

The species was identified in its adult stage according to its morphological characteristics and genitalia. In X. luteola females (Figure 2A), a subconical termination was observed in their last tergite, being larger than in males (Figure 2B), which coincides with what was previously reported by Mustafa et al. (2018). According to this classification, of the total insects collected $(n=395) 21 \%$ were classified as male and $79 \%$ as female. 
Figure 1. Two-pronged fork electrode for electroantennographic detection (EAD) of excised antennae, prepared for recording with a Xanthogaleruca luteola antenna.

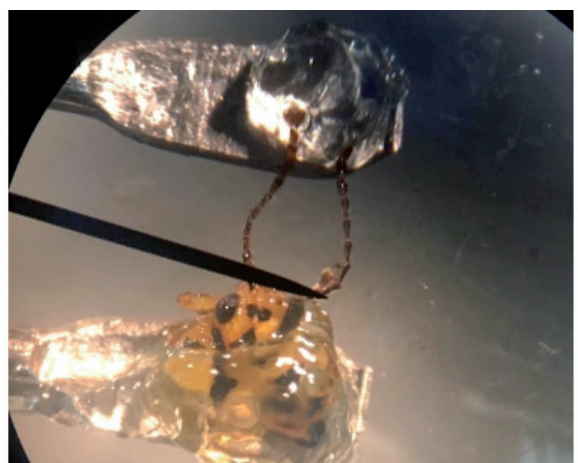

Figure 2. Reproductive structure in Xanthogaleruca luteola adults observed in binocular stereoscopic loupe; females (in dorsal sclerite, observation of sperm) (A) and males and detail of their aedeagus (B).
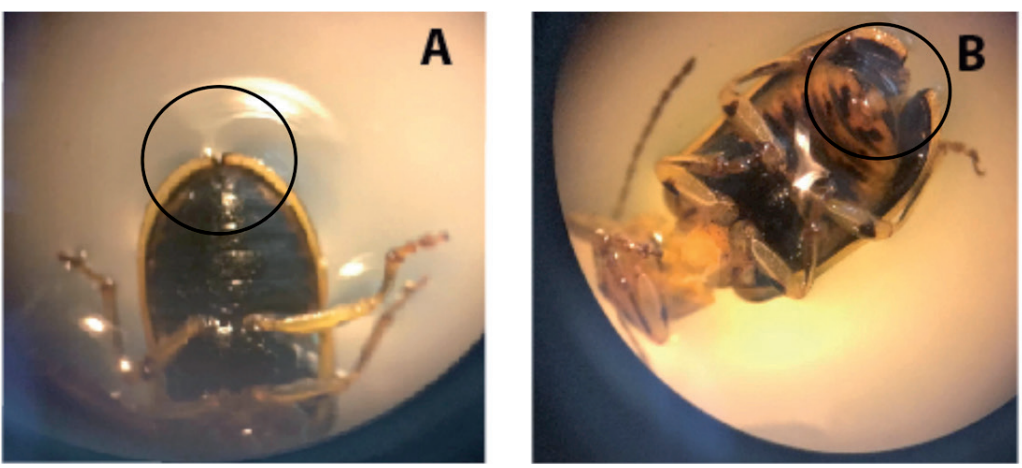

The GC-EAD analysis of the dichloromethane eucalyptus extract using X. luteola female antennae showed a high sensitivity towards different components present in the extract and a strong reaction to 10 components, labeled as $1,2,3$, 4, 5, 6, 7, 8, 9 and 10 (Figure 3A). On the other hand, contrary to the situation of the females, male antennae showed no response (Figure 3B). These results indicate that adult $X$. luteola females are capable of recognizing low-polarity volatile compounds emitted by the eucalyptus species via the antennae that contain specific neuronal receptors located in the sensilla (Bruce and Pickett, 2011).

The number, size, and location of sensillas present in the antennae of $X$. luteola females may explain the high olfactory sensitivity of the response in EAD. This high olfactory sensitivity of females to the volatile compounds emitted by $E$. globulus in EAD studies had not been previously demonstrated.

On the other hand, the retention rate obtained from the use of the Rtx-5 column (Table 1) and the spectra obtained by GC-MS analysis (Figure 4) allowed for the identification of the bioactive compounds present in the extract. The relative percentage was calculated from the total area of the chromatographic peaks and these were ordered according to their elution time.

According to the literature, some secondary metabolites have been identified in E. globulus. These are characterized by the presence of mixtures of terpenes and terpenoids of $\mathrm{C}_{10}$ and $\mathrm{C}_{15}$ (Tyagi and Malik, 2011), which would be the main components of the essential oil, and are found in a variety of plant families in different ratios for each species (Külheim et al., 2011; Bouwer et al., 2014), the eucalyptus species produce a great variety of these volatile compounds in significant amounts, which accumulate in glands distributed in the parenchymal tissue and in the bark of the tree (Özgenc et al., 2017).

Moreover, these compounds have been described with biological activity, activities such as herbivore attractant, repellents or feeding stimulant and that can mediate the behavioral response of insects (Dhifi et al., 2016). $\alpha$-Pinene and 1,8-cineole are the most frequently found monoterpenes in low-polarity extracts from eucalyptus species (Sebei et al., 2015). 
Figure 3. Gas chromatogram (Rtx-5 column) of an extract of eucalyptus with simultaneous detection by flame ionization detector (FID; upper trace) and gas chromatographic-electroantennographic detection (GC-EAD; lower trace) for females (A) and males (B). Arrows indicate the peaks that elicited electrophysiological responses.
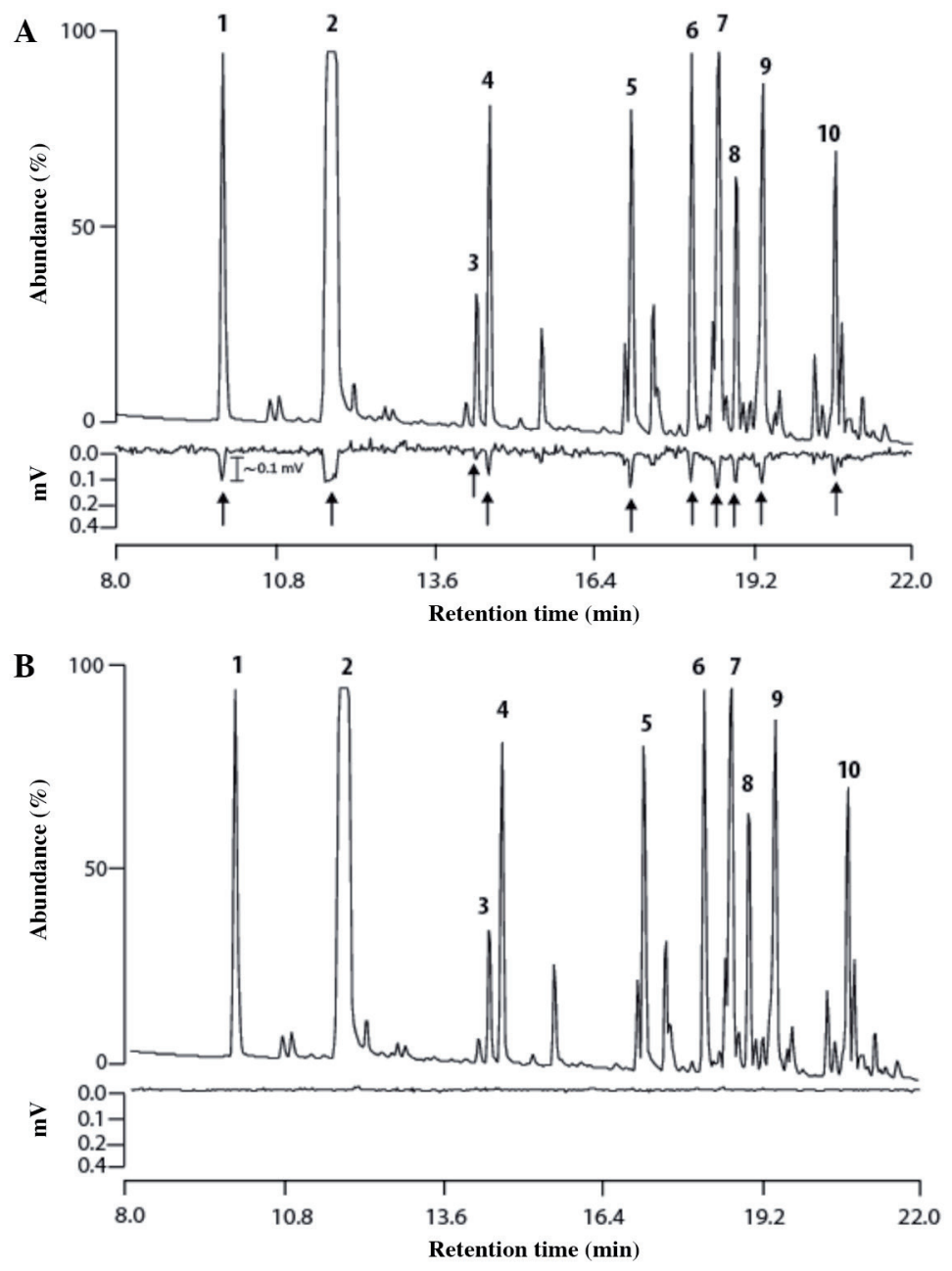

Table 1. Compounds identified in Eucalyptus globulus extract with their respective retention index (RI) and relative content percentage.

\begin{tabular}{|c|c|c|c|c|c|}
\hline & Identified compound & $\begin{array}{c}\text { Calculated } \\
\text { RI }^{\mathrm{a}}\end{array}$ & $\begin{array}{c}\text { Literature } \\
\text { RI }\end{array}$ & Reference & $\begin{array}{l}\text { Relative } \\
\text { content }^{\text {b }}\end{array}$ \\
\hline & & & & & $\%$ \\
\hline 1 & $\alpha$-Pinene & 932 & 932 & Batista-Pereira et al., 2006 & $3.09(0.03)$ \\
\hline 2 & 1,8-cyneol & 1030 & 1028 & Batista-Pereira et al., 2006 & $77.29(1.02)$ \\
\hline 3 & 4-Terpineol & 1179 & 1180 & Cheng et al., 2009 & $0.70(0.01)$ \\
\hline 4 & $\alpha$-Terpineol & 1192 & 1188 & Batista-Pereira et al., 2006 & $2.00(0.07)$ \\
\hline 5 & $\alpha$-Terpineol acetate & 1352 & 1350 & Batista-Pereira et al., 2006 & $3.45(0.52)$ \\
\hline 6 & $\alpha$-Gurjunene & 1419 & 1410 & Rahimi-Nasrabadi et al., 2012 & $3.14(0.42)$ \\
\hline 7 & Aromadendrene & 1450 & 1440 & Rahimi-Nasrabadi et al., 2012 & $4.86(0.01)$ \\
\hline 8 & Alloaromadendrene & 1473 & 1468 & Lawal and Oyedeji, 2009 & $1.43(0.09)$ \\
\hline 9 & Viridiflorene & 1519 & 1520 & Rahimi-Nasrabadi et al., 2012 & $2.57(0.52)$ \\
\hline 10 & Globulol & 1640 & 1623 & Lawal and Oyedeji, 2009 & $1.47(0.06)$ \\
\hline
\end{tabular}

${ }^{a}$ Kovats retention index (Rtx-5 column).

${ }^{\mathrm{b}}$ Area of the identified compounds, mean of three analyses (SD in parentheses). 
Figure 4. Mass spectrometry of the compounds present in the Eucalyptus globulus extract that showed activity by gas chromatographic-electroantennographic detection (GC-EAD).
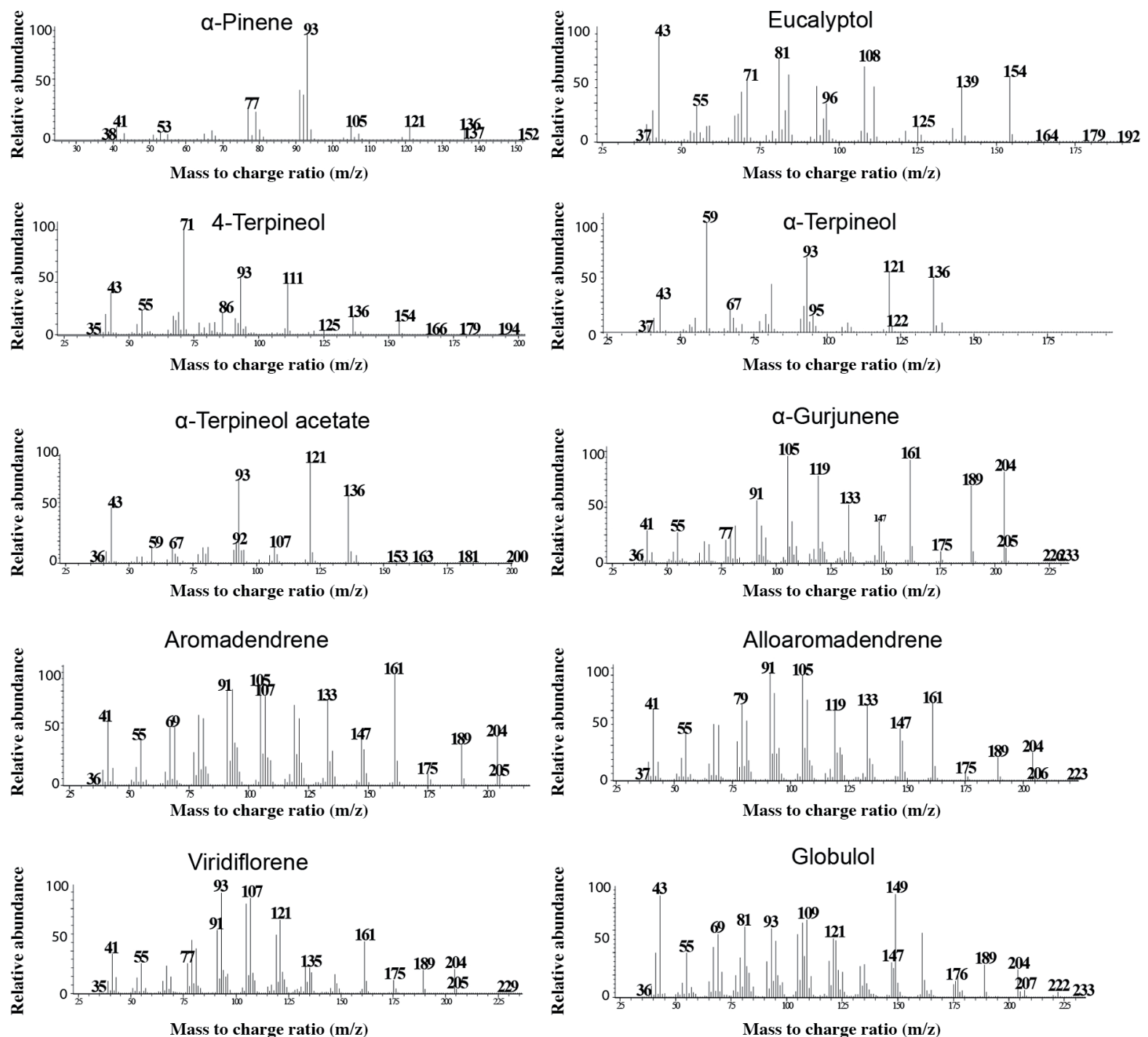

In our research, the main compound was 1,8-cineole (eucalyptol), corresponding to $77.3 \%$ of the total identified compounds and elicited the greatest response in X. luteola female antennae. According to the literature reviewed, 1,8-cineole has not been identified in elm species, which has been described as a host for X. luteola.

This terpene has been reported to have insecticidal activity in the last larval stage of $X$. luteola at a concentrationdependent rate (Adibmoradi et al., 2018). The fact that this compound stimulates the antenna of only female specimens, leads us to infer that it presents a potential role as an allelochemical substance that facilitates the female to choose safe oviposition sites in elm species and not in eucalyptus, using this non-host species as a hibernation site, locating itself in the bark of the trunk and in the roots (Huerta et al., 2011).

In the case of the coleopteran Cosmopolites sordidus, 1,8-cineole is electro-physiologically active and acts as an attractant in Y-tube assay (Boulogne et al., 2012), while $\alpha$-terpineol presents similar signals in the coleopteran Oxyops vitiosa. This suggests that these components provoke an attraction response in adult $X$. luteola females. Moreover, the phenomenon of attraction towards the volatiles emitted by E. globulus and the subsequent damage to this host could imply adverse effects on the economic activities related to the production of this plant species. 
In summary, the choice of the non-host eucalyptus tree by the coleoptera $X$. luteola seems to be stimulated by the $\alpha$-pinene terpenoids, eucalyptol, 4-terpineol, $\alpha$-terpineol, $\alpha$-terpineol acetate, $\alpha$-gurjunene, aromadendrene, alloaromadendrene, viridiflorene and globulol. The role of each of the allelochemicals identified in this research remains to be determined.

\section{CONCLUSIONS}

The fact that 10 components of the essential oil of Eucalyptus globulus were elicited from Xanthogaleruca luteola female antennae indicates that the gas chromatographic-electroantennographic detection (GC-EAD) analysis is a useful method in the detection of active components and contributes to the explanation of the behavior of the insect.

The use of low polarity extracts such as dichloromethane obtained from E. globulus allowed to determine that female insects of the $X$. luteola species are sensitive to at least 10 compounds in the extract, which in decreasing order of concentration are: 1,8-cineole, aromadendrene, $\alpha$-terpineol acetate, $\alpha$-gurjunene, $\alpha$-pinene, viridiflorene, $\alpha$-terpineol, globulol, alloaromadendrene, and 4-terpineol.

The results obtained in the EAD also suggest that the $X$. luteola insect has a highly selective system, capable of distinguishing semi-chemicals from host and non-host species. However, it is necessary to study in depth the role played by each of the allelochemical substances found and whether they are sufficiently attractive and specific in the field for monitoring or controlling the X. luteola population

\section{ACKNOWLEDGEMENTS}

The authors thank to the Laboratory of Chemical Ecology of the Pontificia Universidad Católica de Valparaíso. This research is dedicated to Professor Dr. Vicente Castro-Castillo (RIP).

\section{REFERENCES}

Adibmoradi, G., Sendi, J.J., Tirgari, S., Imani, S., and Razavi-Nematolahi, A. 2018. Effect of 1,8-cineol on the biology and physiology of elm leaf beetle, Xanthogaleruca luteola (Col.: Chrysomelidae). Journal of Plant Protection Research 58(4):420-430. doi:10.24425/jppr.2018.124653.

Batista-Pereira, L., Fernandes, J., da Silva, M., Vieira, P., Bueno, O., and Corrêa, A. 2006. Electrophysiological responses of Atta sexdens rubropilosa workers to essential oils of eucalyptus and its chemical composition. Zeitschrift für Naturforschung C 61:749-755. doi:10.1515/znc-2006-9-1023.

Bergmann, J., Reyes-Garcia, L., Ballesteros, C., Cuevas, Y., Flores, M.F., and Curkovic, T. 2016. Identification of the female sex pheromone of the leafroller Proeulia triquetra Obraztsov (Lepidoptera: Tortricidae). Neotropical Entomology 45(4):351-356. doi:10.1007/s13744-016-0372-3.

Boulogne, I., Petit, P., Ozier-Lafontaine, H., Desfontaines, L., and Loranger-Merciris, G. 2012. Insecticidal and antifungal chemicals produced by plants: a review. Environmental Chemistry Letters 10:325-347. doi:10.1007/s10311-012-0359-1.

Bouwer, M.C., Slippers, B., Wingfield, M.J., and Rohwer, E.R. 2014. Chemical signatures affecting host choice in the Eucalyptus herbivore, Gonipterus sp. (Curculionidae: Coleoptera). Arthropod-Plant Interactions 8(5):439-451. doi:10.1007/s11829-014-9327-y.

Bruce, J.A., and Pickett, J.A. 2011. Perception of plant volatile blends by herbivorous insects - Finding the right mix. Phytochemistry 72(13):1605-1611. doi:10.1016/j.phytochem.2011.04.011.

Büchel, K., Austel, N., Mayer, M., Gershenzon, J., Fenning, T.M., and Meiners, T. 2014. Smelling the tree and the forest: elm background odours affect egg parasitoid orientation to herbivore induced terpenoids. BioControl 59:29. doi:10.1007/s10526-013-9544-9.

Cheng, S., Huang C., Chen, Y., Yu, J., Chen, W., and Chang, S. 2009. Chemical compositions and larvicidal activities of leaf essential oils from two eucalyptus species. Bioresource Technology 100(1):452-456. doi:10.1016/j.biortech.2008.02.038.

Dhifi, W., Bellili, S., Jazi, S., Bahloul, N., and Mnif, W. 2016. Essential oils' chemical characterization and investigation of some biological activities: A critical review. Medicines 3:25. doi:10.3390/medicines3040025.

Huerta H., Chiffelle, I., Puga, K., Azúa, F., Jiménez, R., and Araya, J.E. 2011. Life cycle of Xanthogaleruca luteola (Coleoptera: Chrysomelidae) in Santiago, Chile, and sex fenotype differentiation of adults. Boletín de Sanidad Vegetal de Plagas 37:57-64.

Külheim, C., Yeoh, S.H., Wallis, I.R., Laffan, S., Moran, G., and Foley, W.J. 2011. The molecular basis of quantitative variation in foliar secondary metabolites in Eucalyptus globulus. New Phytologist 191:1041-1053. doi:10.1111/j.1469-8137.2011.03769.x. 
Lawal, O., and Oyedeji, A. 2009. Chemical composition of the essential oils of Cyperus rotundus L. from South Africa. Molecules 14(8):2909-17. doi:10.3390/molecules14082909.

Luna, L., Defagó, M.T., y Salvo, A. 2015. Estudio exploratorio de la interacción Xanthogaleruca luteola - Ulmus spp. en la ciudad de Córdoba. Revista de la Facultad de Ciencias Exactas, Físicas y Naturales 2(1):125-130.

Mustafa, R.A., Hammamurad, H.Q., and Mawlood, N.A. 2018. A new record of Elm Leaf Beetles, Xanthogaleruca luteola (Muller, 1766) (Coleoptera: Chrysomelidae) in Iraq. Journal of Entomology and Zoology Studies 6(5):134-137.

Nahrung, H.F., Loch, A.D., and Matsuki, M. 2016. Invasive insects in Mediterranean forest systems: Australia. Springer, Cham, Switzerland.

Özgenc, Ö., Durmaz, S., Celik, G., Korkmaz, B., and Yayli, N. 2017. Comparative phytochemical analysis of volatile organic compounds by SPME-GC-FID/MS from six coniferous and nine deciduous tree bark species grown in Turkey. South African Journal of Botany 113:23-28. doi:10.1016/j.sajb.2017.07.004.

Rahimi-Nasrabadi, M., Ahmadi, F., and Batooli, H. 2012. Chemical composition of essential oil and in vitro antioxidant activities of the essential oil and methanol extracts of Eucalyptus loxophleba. Natural Product Research 26(7):669-674. doi:10.1080/14786419.2011.593516.

SAG. 2010. Informativo Fitosanitario Forestal N 4 . Informativo del Subdepartamento de Vigilancia y Control Oficial Forestal, División Protección Agrícola y Forestal, Santiago, Chile. Servicio Agrícola y Ganadero (SAG), Santiago, Chile. Available at http://www.sag.cl/sites/default/files/informativo_4.pdf (accessed January 2020).

Sebei, K., Sakouhi, F., Herchi, W., Khouja, M.L., and Boukhchina, S. 2015. Chemical composition and antibacterial activities of seven Eucalyptus species essential oils leaves. Biological Research 48:7. doi:10.1186/0717-6287-48-7.

Tyagi, A.K., and Malik, A. 2011. Antimicrobial potential and chemical composition of Eucalyptus globulus oil in liquid and vapour phase against food spoilage microorganisms. Food Chemistry 126(1):228-235. doi:10.1016/j.foodchem.2010.11.002. 